\title{
Effect of Different Sources of Arbuscular Mycorrhiza on the Performance of Chilli Seedlings
}

\author{
MAbdus Satter* and Delowara Khanam \\ Soil Science Division, Bangladesh Agricultural Research Institute (BARI), Joydebpur, Gazipur 1701, Bangladesh
}

[Received 08 May 2006; Accepted 07 October 2006]

\begin{abstract}
The effect of different sources of arbuscular mycorrhizal (AM) fungi on chilli seedlings was conducted in the net house of Soil Science Division, BARI, Gazipur. The AM fungi from various sources including an exotic variety were included in this study. Soil-based AM inoculum was used at the rate of $\mathbf{5 0} \mathbf{g} /$ pot. It was found that the growth, biomass yield and nutrient uptake of inoculated seedlings were significantly higher than those of uninoculated seedlings. Such higher growth and nutrient uptake appeared to be due to beneficial effects of AM fungi. The performance of the indigenous AM inocula was much better than the exotic inoculum with respect to biomass production and nutrient uptake. Inoculation with AM fungi helped to produce healthy and vigorous seedlings with faster growth. This would help reducing the nursery life and thereby reduce the cost of seedling production. It is expected that the AM inoculated seedlings might perform better in the field trail since the fungi could colonize with the roots.
\end{abstract}

Keywords: Arbuscular mycorrhiza, Chilli seedlings, Pot culture

\section{Introduction}

The arbuscular mycorrhiza (AM) fungi are beneficial fungi forming symbiotic association with roots of the most plant species and help them in uptake of nutrients and moisture from the soil ${ }^{1}$. A part of fungal mycelia enters inside the cortical region of plant roots and the other part remains outside the root surface and extends in the rhizosphere soil. The external mycelium functions as the extension of the root hairs. They absorb nutrients and moisture from the rhizosphere soil and transfer them into the host plant through arbuscules in the cortical cells. Thus AM fungi help plants in absorbing nutrients and moisture from the soil and in turn they receive energy from the host plants. The external AM hyphae extend several centimetres from the infected root surface and help in exploration of greater soil volume to absorb more nutrients and moisture from the soil. Besides, they increase the rate of photosynthesis of the host plants ${ }^{2}$. They also enhance production of growth regulating substances in the host plants ${ }^{3}$. They improve phosphorus (P) uptake from less soluble sources like phosphate rocks and also from the fixed forms like Fe- and Al-phosphates ${ }^{4}$. Furthermore, they help plants in uptake of other nutrients as well ${ }^{1}$. The AM fungi also help plants in resisting soil-borne root diseases ${ }^{5-6}$. Thus the fungi might be helpful in controlling damping off disease of chilli seedlings in the nursery. The effectiveness of AM fungi varies with the ecology of their habitat.

Healthy and vigorous seedlings are pre-requisite for harvesting a good crop of chilli. Because of the many benefits, AM fungi might be helpful in producing healthy and vigorous chilli seedlings. They may also reduce the nursery life by enhancing faster growth of seedlings. The mycorrhizal seedlings are also expected to perform better in the field because the AM fungi could be carried over to the field with infected roots. The present investigation was undertaken to observe the effect of different sources of AM fungi on the performance of chilli seedlings, to identify better source(s) of AM for producing chilli seedlings, and to produce chilli seedlings with AM colonization.

\section{Materials and Methods}

A nursery pot-plantation study on the effect of different sources of AM fungi on chilli seedlings was conducted in the net house of Soil Science Division, BARI, Gazipur from the $4^{\text {th }}$ week of April to $1^{\text {st }}$ week of June, 2003. One kilogram of silted soils (sandy clay loam) from the bank of Turag River at Kodda, Gazipur was mixed with cow dung at a ratio of 5:1 per pot. The mixture was sterilized with $10 \%$ formaldehyde solution to inactivate the native AM fungi and other organisms. Sterilized mixture $(1 \mathrm{~kg})$ was used per pot as the potting medium. The physical and chemical properties of the soil had been reported earlier ${ }^{7}$. The soil was slightly alkaline in reaction. The organic matter, major nutrients and zinc and copper contents of the soil were low, while the boron and manganese levels were quite high.

The experiment was laid out in randomised complete block design (RCBD) with four replications. Effect of AM fungi, collected from Jamalpur, Joydebpur, Ishurdi and Hathazari, their mixture and an

*Corresponding author:

Dr. M Abdus Satter, Principal Scientific Officer (Soil), Bangladesh Agricultural Research Council (BARC), Farmgate, Dhaka 1215, Bangladesh

Tel (Office): (02) 9132411; Cell: 0171 6420890; E-mail: satterbari@yahoo.com 
exotic source (India), on seedling development of chilli variety Bangla Lanka-1 was studied. Perforated black polythene bags were used as the pot. A hole of $6 \mathrm{~cm}$ in diameter and $5 \mathrm{~cm}$ in depth was dug at the centre of the potting medium. The soil-based AM inoculum at the rate of $50 \mathrm{~g} /$ pot containing 105-120 spores/100 g inoculum along with infected root pieces of the host plants was placed in the hole. A soil layer of about $1 \mathrm{~cm}$ was spread on the inoculum layer. Chilli seeds were sown in the soil layer above the inoculum to ensure penetration of the roots through the inoculum layer immediately after germination. The seedlings were thinned out within a week of germination keeping five uniform seedlings per pot. Watering and other intercultural operations were done when necessary.

Biomass yield and yield components of seedlings were recorded on the day of harvesting. Seedling height was measured from the soil layer to the tip of the stem. Collar diameter was measured with a slide callipers $1 \mathrm{~cm}$ above the soil layer. The seedlings were harvested carefully by uprooting at an age of 44 days after sowing (DAS). The roots were washed to remove the adhered soils. Root samples were then excised for AM colonization studies. Fresh weight of the seedlings was recorded. The seedlings were then oven dried to a constant weight at a temperature of $70^{\circ} \mathrm{C}$ and the dry weight was recorded. The dried plant samples were ground and used for chemical analysis.

Soil samples from the pot were collected during harvesting the seedlings for counting AM spore population. Hundred grams soil sample per pot was used to count the spore numbers. The spore numbers were determined by Wet Sieving and Decanting method $^{8}$. To assess AM root colonization, the roots were processed according to Koske and Gemma ${ }^{9}$ and observed under a compound microscope. Presence of fungal bodies (mycelium, spores, arbuscules and vesicles) in the root tissues was considered as positive for infection. Percent root colonization was calculated as follows:

$$
\text { Root colonization }=\frac{N+v e}{N} \times 100(\%)
$$

where, $N+v e=$ No. of AM positive segments, $\mathrm{N}=$ Total No. of segments observed

\section{Results and Discussion}

\section{Performance of seedlings}

Performance of chilli seedlings with different sources of AM inoculum is as presented in Table 1. Biomass yield and yield components of the inoculated chilli seedlings were significantly higher than that of the uninoculated seedlings irrespective of the inoculum sources. The local AM inoculum sources and their mixture produced identical number of leaves per plant, collar diameter and fresh and dry weights of chilli seedlings, which were significantly higher than those with the exotic source and control. Seedling height was found highest with inoculum source from Hathazari but it was identical to those with Joydebpur and Ishurdi sources and superior to those with the remaining two sources.
Table 1. Effect of different sources of arbuscular mycorrhiza (AM) inoculum on biomass yield and yield components of chilli seedlings

\begin{tabular}{lcccccc}
\hline $\begin{array}{l}\text { Source } \\
\text { of AM }\end{array}$ & $\begin{array}{c}\text { Seedling } \\
\text { height } \\
(\mathrm{cm})\end{array}$ & $\begin{array}{c}\text { No. of } \\
\text { leaves/ } \\
\text { plant }\end{array}$ & $\begin{array}{c}\text { Collar } \\
\text { diameter } \\
(\mathrm{mm})\end{array}$ & $\begin{array}{c}\text { Fresh } \\
\text { weight } \\
(\mathrm{g} / \text { plant })\end{array}$ & $\begin{array}{c}\text { Dry } \\
\text { weight } \\
(\mathrm{mg} / \mathrm{plant})\end{array}$ & $\begin{array}{c}\text { Dry } \\
\text { weight } \\
\text { increased } \\
(\%)\end{array}$ \\
\hline Jamalpur & $12.6^{\mathrm{bc}}$ & $7.7^{\mathrm{a}}$ & $1.30^{\mathrm{ab}}$ & $1.24^{\mathrm{a}}$ & $155^{\mathrm{a}}$ & 260 \\
Joydebpur & $13.4^{\mathrm{ab}}$ & $7.8^{\mathrm{a}}$ & $1.40^{\mathrm{ab}}$ & $1.54^{\mathrm{a}}$ & $188^{\mathrm{a}}$ & 337 \\
Ishurdi & $13.4^{\mathrm{ab}}$ & $8.2^{\mathrm{a}}$ & $1.48^{\mathrm{a}}$ & $1.42^{\mathrm{a}}$ & $170^{\mathrm{a}}$ & 295 \\
Hathazari & $14.4^{\mathrm{a}}$ & $8.5^{\mathrm{a}}$ & $1.35^{\mathrm{ab}}$ & $1.56^{\mathrm{a}}$ & $187^{\mathrm{a}}$ & 335 \\
$\begin{array}{l}\text { Local } \\
\text { mixure }\end{array}$ & $11.9^{\mathrm{cd}}$ & $7.3^{\mathrm{a}}$ & $1.28^{\mathrm{ab}}$ & $1.34^{\mathrm{a}}$ & $144^{\mathrm{ab}}$ & 235 \\
Exotic & $10.8^{\mathrm{d}}$ & $6.0^{\mathrm{b}}$ & $1.20^{\mathrm{b}}$ & $0.86^{\mathrm{b}}$ & $80^{\mathrm{bc}}$ & 86 \\
Control & $6.3^{\mathrm{e}}$ & $4.3^{\mathrm{c}}$ & $0.80^{\mathrm{c}}$ & $0.44^{\mathrm{c}}$ & $43^{\mathrm{c}}$ & \\
F-Test & $* *$ & $* *$ & $* *$ & $* *$ & $* *$ & \\
\hline
\end{tabular}

Superior performance of the inoculated seedlings might be due to the beneficial effects of AM fungi. There are many evidence of better performance of AM inoculated seedlings compared to those without inoculation ${ }^{10-11}$. Better performance of the seedlings with local AM inoculum sources compared to that with exotic source might be due to differences in the activity and virulence of AM fungi among these sources. Khanam ${ }^{12}$ observed wide variation in AM fungi species composition among different agro-ecological situation. Such variation in AM fungi species composition between the local and exotic sources might have been influenced the performance of chilli seedlings differently.

\section{Mycorrhizal development}

Effect of different sources of AM inoculum on root colonization by AM fungi and spore numbers in rhizosphere soils of chilli seedlings are as presented in Table 2. Root colonization by AM fungi from local sources was found identical, which was superior to that from the exotic source. There was also some root colonization in the control plants with native AM fungi. This might be due to survival of some native AM fungi even after sterilizing the soil. The highest number of spores in the rhizosphere soils was found with the inoculum source from Ishurdi, which was identical to those with the other local sources but superior to those with the exotic source and control. Rhizosphere soils from control plants also contained some AM spores because of some root colonization with the native AM fungi.

Table 2. Effect of different sources of arbuscular mycorrhiza (AM) inoculum on root colonization by AM fungi and spore numbers in rhizosphere soils of chilli seedlings

\begin{tabular}{lcc}
\hline Inoculum source & $\begin{array}{c}\text { Root } \\
\text { colonization (\%) }\end{array}$ & $\begin{array}{c}\text { Spore count } \\
(\text { No./100 g soil) }\end{array}$ \\
\hline Jamalpur & $53^{\mathrm{a}}$ & $66^{\mathrm{abc}}$ \\
Joydebpur & $53^{\mathrm{a}}$ & $65^{\mathrm{abc}}$ \\
Ishurdi & $55^{\mathrm{a}}$ & $96^{\mathrm{a}}$ \\
Hathazari & $55^{\mathrm{a}}$ & $78^{\mathrm{ab}}$ \\
Local mixture & $40^{\mathrm{ab}}$ & $67^{\mathrm{abc}}$ \\
Exotic & $25^{\mathrm{b}}$ & $38^{\mathrm{cd}}$ \\
Control & $3^{\mathrm{c}}$ & $7^{\mathrm{d}}$ \\
F-Test & $* *$ & $* *$ \\
\hline
\end{tabular}


A significant positive linear relationship between the AM root colonization and biomass yield of chilli seedlings was observed (Figure 1). This indicates the efficiency of AM fungi in enhancing biomass production of chilli seedlings. The external AM hyphae of mycorrhizal roots are known to function as the extension of root hairs and help plants to absorb and translocate nutrients to the host plants from soil outside the root depletion zone of nonmycorrhizal plants. The external hyphae can extend up to several centimetres beyond the mycorrhizal root surface and can increase root surface area and the absorption zone for exploration of greater soil volume for nutrient and moisture uptake ${ }^{13}$. Mycorrhizal fungal hyphae were found to intercept labelled P placed $27 \mathrm{~cm}$ apart from a mycorrhizal root, whereas it remained unavailable to nonmycorrhizal roots ${ }^{14}$. The radius of the depletion zone for $\mathrm{P}$ around mycorrhizal onion roots was found twice that for non-mycorrhizal roots $^{15}$.

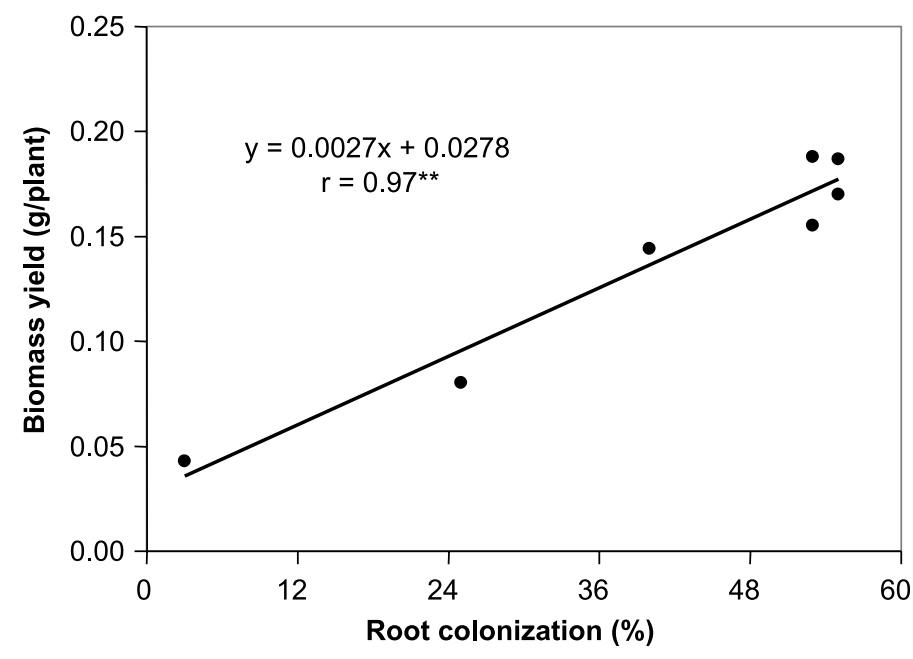

Figure 1. Relationship between arbuscular mycorrhiza (AM) root colonization and biomass yield of chilli seedlings.

The rate of nutrient uptake by mycorrhizal roots is also faster than that by non-mycorrhizal roots ${ }^{16}$. There are reports that the rate of inflow of $\mathrm{P}$ through AM hyphae is six times the rate of inflow into normal root hairs ${ }^{17}$. All these factors enabled the AM inoculated chilli seedlings in the present study to absorb more nutrients and thereby to enhance faster growth and produce more biomass compared to the uninoculated seedlings.

\section{Nutrient uptake}

Effect of different sources of AM inoculum on uptake of major nutrients and micronutrients by chilli seedlings is presented in Table 3 and Table 4 respectively. Uptake of almost all the major nutrients by chilli seedlings inoculated with local sources was significantly higher than those with exotic source and control. A conservative estimate suggests that up to $25 \%$ of plant N, $80 \%$ of P, $10 \%$ of K, $25 \%$ of $\mathrm{Zn}$ and $60 \%$ of $\mathrm{Cu}$ might be supplied by mycorrhizal hyphae to the plants ${ }^{1}$. Euterpe oleracea was found to absorb $191 \%$ higher of N, $664 \%$ of P, $46 \%$ of K, $562 \%$ of Ca and $363 \%$ higher of Mg through symbiosis with AM fungi ${ }^{18}$. Uptake of micronutrients in the present study was also significantly higher with AM inoculum from the local sources and with their mixture compared to those with the exotic source and control. Among the local sources micronutrient nutrient uptake with Jamalpur source was lower than that with the remaining three sources. Nutrient utilization efficiency of AM inoculated seedlings in producing biomass is also reported to be higher than those of uninoculated seedlings ${ }^{10}$. For example, $\mathrm{P}$ utilization efficiency (PUE) of AM inoculated Acacia mangium seedlings ( $0.330 \mathrm{~g}$ biomass/mg P) was found significantly higher than that of uninoculated seedlings $(0.264 \mathrm{~g} \text { biomass } / \mathrm{mg} \mathrm{P})^{11}$. Better performance of chilli seedlings with AM inoculation in the present study might be due to higher uptake of nutrients and their efficient utilization in producing biomass.

Table 3. Effect of different sources of arbuscular mycorrhiza (AM) inoculum on uptake of major nutrients by chilli seedlings

\begin{tabular}{lccccc}
\hline Source of AM & \multicolumn{5}{c}{ Nutrient uptake (mg/plant) } \\
\cline { 2 - 6 } & $\mathrm{P}$ & $\mathrm{K}$ & $\mathrm{Ca}$ & $\mathrm{Mg}$ & $\mathrm{S}$ \\
\hline Jamalpur & $0.39^{\mathrm{ab}}$ & $4.67^{\mathrm{a}}$ & $1.35^{\mathrm{a}}$ & $0.79^{\mathrm{ab}}$ & $1.76^{\mathrm{a}}$ \\
Joydebpur & $0.36^{\mathrm{abc}}$ & $4.63^{\mathrm{a}}$ & $1.51^{\mathrm{a}}$ & $0.89^{\mathrm{ab}}$ & $2.06^{\mathrm{a}}$ \\
Ishurdi & $0.49^{\mathrm{a}}$ & $4.89^{\mathrm{a}}$ & $1.43^{\mathrm{a}}$ & $0.84^{\mathrm{ab}}$ & $2.09^{\mathrm{a}}$ \\
Hathazari & $0.48^{\mathrm{a}}$ & $5.22^{\mathrm{a}}$ & $1.58^{\mathrm{a}}$ & $0.96^{\mathrm{a}}$ & $2.26^{\mathrm{a}}$ \\
Local mixture & $0.32^{\mathrm{bc}}$ & $4.08^{\mathrm{a}}$ & $1.31^{\mathrm{a}}$ & $0.67^{\mathrm{b}}$ & $1.61^{\mathrm{a}}$ \\
Exotic & $0.23^{\mathrm{c}}$ & $2.10^{\mathrm{b}}$ & $0.65^{\mathrm{b}}$ & $0.36^{\mathrm{b}}$ & $0.89^{\mathrm{b}}$ \\
Control & $0.09^{\mathrm{d}}$ & $1.16^{\mathrm{b}}$ & $0.39^{\mathrm{b}}$ & $0.21^{\mathrm{c}}$ & $0.50^{\mathrm{b}}$ \\
F-Test & $* *$ & $* *$ & $* *$ & $* *$ & $* *$ \\
\hline
\end{tabular}

Table 4. Effect of different sources of arbuscular mycorrhiza (AM) inoculum on uptake of micronutrients by chilli seedlings

\begin{tabular}{lccccc}
\hline Source of AM & \multicolumn{5}{c}{ Nutrient uptake $(\mu \mathrm{g} /$ plant $)$} \\
\cline { 2 - 6 } & $\mathrm{B}$ & $\mathrm{Cu}$ & $\mathrm{Zn}$ & $\mathrm{Fe}$ & $\mathrm{Mn}$ \\
\hline Jamalpur & $3.63^{\mathrm{c}}$ & $1.55^{\mathrm{bc}}$ & $4.95^{\mathrm{a}}$ & $32.9^{\mathrm{c}}$ & $6.05^{\mathrm{b}}$ \\
Joydebpur & $7.28^{\mathrm{a}}$ & $2.05^{\mathrm{ab}}$ & $7.03^{\mathrm{b}}$ & $40.7^{\mathrm{a}}$ & $6.73^{\mathrm{ab}}$ \\
Ishurdi & $7.05^{\mathrm{a}}$ & $1.13^{\mathrm{cd}}$ & $7.13^{\mathrm{b}}$ & $37.2^{\mathrm{b}}$ & $6.15^{\mathrm{b}}$ \\
Hathazari & $7.38^{\mathrm{a}}$ & $2.23^{\mathrm{a}}$ & $8.70^{\mathrm{a}}$ & $40.9^{\mathrm{a}}$ & $7.33^{\mathrm{a}}$ \\
Local mixture & $5.95^{\mathrm{b}}$ & $1.53^{\mathrm{bc}}$ & $5.93^{\mathrm{c}}$ & $31.4^{\mathrm{d}}$ & $6.10^{\mathrm{b}}$ \\
Exotic & $1.90^{\mathrm{d}}$ & $0.70^{\mathrm{de}}$ & $3.15^{\mathrm{e}}$ & $17.1^{\mathrm{e}}$ & $2.90^{\mathrm{c}}$ \\
Control & $1.73^{\mathrm{d}}$ & $0.38^{\mathrm{e}}$ & $1.80^{\mathrm{f}}$ & $9.8^{\mathrm{f}}$ & $1.75^{\mathrm{d}}$ \\
F-Test & $* *$ & $* *$ & $* *$ & $* *$ & $* *$ \\
\hline
\end{tabular}

From the results it is evident that AM fungi have the potential to improve uptake of all the nutrients and thereby to enhance faster growth of chilli seedlings. Such improvement in nutrient uptake also enhanced production of healthy and vigorous seedlings. Faster growth of seedlings might help to shorten the nursery life, and thereby would reduce the cost of seedling production. The AM inoculated seedlings might also perform better in the field because the AM fungi could be carried over to the field through the colonized roots. All the local AM inoculum sources were almost equivalent and were much better than the exotic source in respect of biomass production and nutrient uptake. 


\section{References}

1. Marschner H \& Dell B. 1994. Nutrient uptake in mycorrhizal symbiosis. Plant Soil. 159: 89-102.

2. Syvertsen JP \& Graham JH. 1999. Phosphorus supply and arbuscular mycorrhizas increase growth and net gas exchange response in two Citrus species grown at elevated $\mathrm{CO}_{2}$. Plant Soil. 208: 209-219.

3. Danneberg G, Latus C, Zimmer W, Hundes-Hagen B, SchneiderPoetsch H \& Bothe H. 1992. Influence of vesicular-arbuscular mycorrhiza on phytohormone balances in maize (Zea mays L). J Plant Physiol. 141: 33-39.

4. Bolan NS. 1991. A critical review on the role of mycorrhizal fungi in the uptake of phosphorus by plants. Plant Soil. 134: 189-207.

5. Bethelenfalvay GJ \& Linderman RG. 1992. Mycorrhizae in Sustainable Agriculture. American Society of Agronomy Special Publication No. 54, Medison.

6. Ho CT. 1998. Safe and efficient management systems for plantation pests and diseases. The Planter. 74: 369-385.

7. Satter MA \& Khanam D. 2005. Effect of arbuscular mycorrhiza on germination of chilli and brinjal seeds. Bangladesh J Microbiol. 22(2): 93-95.

8. Gerdemann JW \& Nicolson TH. 1963. Spores of mycorrhizal endogone extracted from soil by wet sieving and decanting. Trans Brit Mycol Soc. 46: 235-244.

9. Koske RE \& Gemma JN. 1989. A modified procedure for staining roots and detect VA mycorrhizas. Mycol Res. 92: 486-505.

10. Masri BM. 1997. Mycorrhizal inoculation for growth enhancement and improvement of the water relations in mangosteen (Garcinia mangostana L) seedlings. PhD Thesis. Universiti Putra Malaysia, Serdang, Malaysia.

11. Satter MA. 2000. The arbuscular Mycorrhiza and phosphate rock in rehabilitation of tin tailings with Acacia mangium and peanut agroforestry system. PhD Thesis. Faculty of Agriculture, Universiti Putra Malaysia, Serdang, Malaysia.

12. Khanam D. 2002. Biodiversity of arbuscular mycorrhizal fungi in agricultural crops and their interaction with Rhizobium on chickpea (Cicer ariatinum L). PhD Thesis. Department of Soil Science, Bangabandhu Sheikh Mujibur Rahman Agricultural University, Gazipur, Bangladesh.

13. Johansen A, Jacobsen I \& Jensen ES. 1993. External hyphae of vesicular-arbuscular mycorrhizal fungi associated with Trifolium subterraneum L. 3. Hyphal transport of ${ }^{32} \mathrm{P}$ and ${ }^{15} \mathrm{~N}$. New Phytol. 124: 61-68.

14. Hattingh MJ, Gray LE \& Gerdemann JW. 1973. Uptake and translocation of ${ }^{32} \mathrm{P}$ labelled phosphate to onion roots by endomycorrhizal fungi. Soil Sci. 116: 383-387.

15. Owusu-Bennoah E \& Wild A. 1980. Effects of vesicular-arbuscular mycorrhiza on the size of the labile pool of soil phosphate. Plant Soil. 54: 233-242.

16. Son CL \& Smith SE. 1988. Mycorrhizal growth responses: interaction between photon irradiance and phosphorus nutrition. New Phytol. 108: $305-314$.

17. Sanders FE \& Tinker PBH. 1973. Phosphate flow into mycorrhizal roots. Pestic Sci. 4: 385-395.

18. Chu EY. 1999. The effect of arbuscular mycorrhizal fungi inoculation on Euterpe oleracea Mart seedlings. Pesqui Agropecu Bras. 34: 10191024. 